\title{
La objeción de conciencia de los profesionales de la salud y el aborto legal en Argentina ${ }^{(1)}$
}

\author{
Débora Ranieri de Cechini \\ Universidad Católica Argentina, Facultad de Derecho, CABA, Argentina \\ $\bigotimes$ dranieri@uca.edu.ar \\ Sofía Calderone \\ Universidad Católica Argentina, Facultad de Derecho, CABA, Argentina \\ $\bigotimes$ sofiacalderone@uca.edu.ar \\ 迤- Fecha de recepción: 04/08/2021 - Fecha de aceptación: 16/11/2021
}

Cómo citar este artículo: Ranieri de Cechini, D. y Calderone, S. (2022).
La objeción de conciencia de los profesionales de la salud y el aborto le-
gal en Argentina. Revista Perspectivas de las Ciencias Económicas y Jurídi-
cas. Vol. 12, No 1 (enero-junio). Santa Rosa: FCEyJ (UNLPam); EdUNLPam;
pp. 81-102. ISSN 2250-4087, e-ISSN 2445-8566 DOI http://dx.doi.org/10.19137/
perspectivas-2022-v12n1a06
Resumen: En 2020, el Congreso Nacional legalizó el aborto en Argentina.
La norma, aprobada en el marco de fuertes debates, se hace cargo de las
disyuntivas que dicho procedimiento causa a los profesionales de la salud.
De ese modo, reconoce -aunque de modo restrictivo- la objeción de con-
ciencia para el personal sanitario. En este trabajo, se reflexiona sobre este
derecho y las razones que fundan su resguardo en la medicina. Para ello,

(1) El artículo corresponde al Proyecto de Investigación IUS 2019-2021, "Libertad religiosa: la objeción de conciencia institucional o el derecho de autonomía de las instituciones y el acomodamiento razonable. Una mirada desde la jurisprudencia nacional y el derecho comparado" (Facultad de Derecho, UCA). Agradecemos a los profesionales de la salud que integran la Red de Objetores de Conciencia Argentina, quienes supieron transmitirnos las preocupaciones y dificultades provocadas por la legalización del aborto en el quehacer médico e institucional cotidiano. Para resguardar su privacidad, no mencionaremos sus nombres. 
las autoras proponen el siguiente recorrido: inicialmente, se delineará el concepto de objeción de conciencia; se indagará acerca de la protección de la objeción de conciencia frente al aborto en Argentina y sus alcances; luego, se ahondará en la importancia de su aseguramiento en la medicina, desde dos perspectivas: primero, desde una consideración de los objetivos esenciales de esa ciencia, y segundo, a partir de una mirada sobre la naturaleza de la relación entre el médico y el paciente; al final, se apuntarán algunas observaciones críticas a la regulación actual.

Palabras clave: objeción de conciencia; aborto; libertad de conciencia.

\title{
Health care professionals' freedom of conscience and legal abortion in Argentina
}

\begin{abstract}
In 2020, Argentina passed an act that legalized abortion for the first time in this country. Although in a restrictive way, the legislative body considered the dilemmas caused by legal abortion among health care professionals. Consequently, the new act contemplates conscientious objection for medical workers in a restrictive clause. This paper addresses the definition of this civil liberty and the reasons underlying its protection in medicine. To achieve that ending, the authors propose the following route: first, we focus on the concept of conscientious objection and its evolution and classification; then, legal protection of conscientious objection against abortion is examined; also, the importance of its protection in medicine, from two perspectives: first, in relation with the aims of the medical science; second, from the perspective of the doctor-patient relationship; finally, we include some critical observations about the consequences of the current regulation.
\end{abstract}

Key words: conscience objection; abortion, freedom of conscience.

\section{A objeção de consciência de profissionais de saúde e o aborto legal na Argentina}

Resumo: Em 2020, o Congresso Nacional legalizou o aborto na Argentina. A norma, aprovada no marco de fortes debates, atende aos dilemas que esse procedimento acarreta aos profissionais de saúde. Desta forma, reconhece -ainda que de forma restritiva- a objeção de consciência para o pessoal de saúde. Neste trabalho, refletimos sobre esse direito e os motivos de sua proteção na medicina. Para isso, os autores propõem o seguinte caminho: inicialmente, será delineado o conceito de objeção de consciência; inquirirá sobre a proteção da objeção de consciência contra o aborto na Argentina e seu alcance; a seguir, se aprofundará na importância de seu seguro na medicina, a partir de duas perspectivas: primeiro, a partir da consideração dos objetivos essenciais dessa ciência, segundo, a partir de um olhar sobre a natureza da relação entre o médico e paciente; ao final, serão feitas algumas observações críticas sobre a regulamentação em vigor.

Palavras-chave: objeção de consciência; aborto; liberdade de consciência.

\section{Introducción}

El 24 de enero de 2021 comenzó a regir la Ley 27.610 de Acceso a la Interrupción Voluntaria del Embarazo -IVE- (BO, 15/01/2021).(2) Por primera vez, la norma insertó en nuestro sistema legal el aborto a voluntad hasta la semana 14, inclusive,

(2) Por resolución 1535/2021 (BO, 28/05/2021), el Ministerio de Salud emitió el Protocolo para la Atención Integral de las Personas con Derecho a la Interrupción Voluntaria y Legal del Embarazo (actualización 2021), y lo incorporó al Programa Nacional de Garantía de Calidad de la Atención Médica -art. 2-- (en adelante, Protocolo 2021). La reglamentación se aprobó por el decreto 516/2021 (BO 14/08/2021). 
y mantuvo la no punibilidad por causales -si el embarazo fuere resultado de una violación o si estuviere en peligro la vida o la salud de la mujer- sin ningún otro límite. (3)

La ley, que se erige tan permisiva con los deseos de la mujer, al mismo tiempo acorrala a los miembros del personal sanitario, con cargas y obligaciones contrarias al quehacer de su profesión. ${ }^{(4)}$ Más temprano que tarde, quienes se desempeñan en el ámbito de la salud se enfrentarán a los riesgos y dilemas ${ }^{(5)}$ de la legalización de una práctica que hasta hace poco era considerada un delito contra la vida de la persona por nacer (y que todavía lo es en determinados supuestos). ${ }^{(6)}$

No es de extrañar que médicos, enfermeros, obstetras, farmacéuticos, psicólogos y asistentes sociales, entre otros, se encuentren atravesados por dudas morales, religiosas y también científicas y legales, a menudo dramáticas, sobre la legitimidad de intervenir en el procedimiento. ${ }^{(7)}$ Una primera respuesta a tales interrogantes se encuentra en la misma ley 27.610, que contempla en forma expresa el derecho a la objeción de conciencia de los profesionales de la salud (arts. 10 y 11).

En estas circunstancias, parece oportuno reflexionar sobre este derecho, las razones que fundan su resguardo en la medicina y las dificultades que se presentan

(3) Cfr. arts. $2^{\circ}, 3^{\circ}, 4^{\circ}, 5^{\circ}$ y cc de la ley 27.610. El art. 4ㅇe establece en sus incs. a) y b) las causales que habilitan el aborto más allá de las 14 semanas. Tal y como fue aprobada por el Congreso, el inc. b) refería a la "salud integral". El calificativo "integral" fue "observado" por el decreto de promulgación (decreto PEN 14/2021, BO 15/01/2021). Sobre los efectos del veto ver Lafferriere (2020a).

(4) Las cargas atribuidas al personal sanitario están dispersas en la ley y refieren al deber de asegurar el acceso al aborto dentro de los 10 días desde que les fuera requerido (art. $5^{\circ}$ ), de garantizar el trato digno, la privacidad, la confidencialidad, la autonomía de la voluntad, el acceso a la información, la calidad de atención (art. 5) y de capacitación (art. 19).

(5) Apenas comenzó a regir el aborto legal, el secretario de salud de General Viamonte, provincia de Buenos Aires, Dr. Santiago Catalán Pellet, renunció a su cargo. En una carta explicó los motivos: “... [e]s imposible no reconocer la sanción de la Ley 27.610 (...) como causa de mi renuncia. Esta ley obliga a las autoridades del sistema público de salud a tomar medidas que van absolutamente en contra de mis convicciones y atentan contra el juramento que hice el día en el que me recibí" (como se citó en Costa, 2021).

(6) Cfr. art. 85 y ss. del Código Penal (BO, 03/11/1921), modificados por la nueva norma. Como decíamos, la nueva ley mantiene tipificado el aborto como delito contra la vida: a) si quien lo lleva adelante obra sin el consentimiento de la embarazada (art. 85, inc. 1, CP); b) si, mediando el consentimiento de la mujer, se realizara luego de la semana 14 en ausencia de las causales de no punibilidad previstas por el art. 86 (art. 85, inc. 2, CP); c) también se encuentra tipificada la conducta de aquel que con violencia causare un aborto "sin haber tenido el propósito de causarlo, si el estado del embarazo de la persona gestante fuere notorio o le constare" (art. 87, inc. 2, CP) y d) la conducta de la mujer que causare su propio aborto, o que consienta que otro se lo cause, luego de la semana 14 y siempre que no medien las causales de no punibilidad de la ley, aunque se admite la eximición de la pena "cuando las circunstancias hicieran excusable la conducta". La tentativa de la mujer no es punible (art. 88 CP).

(7) El 24 de agosto de 2020 se realizó el conversatorio virtual "La objeción de conciencia del médico frente al aborto", en la Facultad de Derecho de la Universidad Católica Argentina. Solo en la plataforma Zoom hubo más de 300 asistentes. El número de participantes, antes de la sanción de la ley 27.610, es una prueba cabal de la preocupación de los agentes de salud. La crónica de lo acontecido fue plasmada por la pluma de Riccardi (2020). 
por el modo en que ha sido legislada. Para ello, seguiremos este recorrido: inicialmente, se delineará una definición del concepto de objeción de conciencia; a continuación se indagará acerca de la protección de la objeción de conciencia frente al aborto en Argentina; luego, se ahondará en la importancia de su aseguramiento en el área de la medicina, desde dos perspectivas: primero, a partir de una consideración sobre la finalidad esencial de esa ciencia, y segundo, a través de un acercamiento a la lógica relacional del médico y el paciente; al final, apuntaremos algunas observaciones críticas a la regulación actual. ${ }^{\left({ }^{8}\right)}$

\section{Definiciones iniciales}

La objeción de conciencia es el derecho de "incumplir" un mandato legal que resulta contrario a las convicciones éticas, morales o religiosas del objetor (Navarro Floria, 2004, p. 25). No es un acto político, mucho menos un avasallamiento de los derechos de terceros. El objetor no busca hacer prevalecer en los demás su visión del mundo: simplemente pretende evitar, de forma pacífica, la cooperación en acciones que violentan su conciencia. ${ }^{(9)}$

Desde ya que la conciencia no es una mera excusa para hacer y deshacer a voluntad; sino que obrar según la propia conciencia se impone (ante todo) como un deber que surge de un juicio moral (práctico), por ende, racional.(10) De eso se sigue el requisito de la sinceridad del objetor, a quien le corresponde "dar razones fundadas de su objeción" y probar que son "coherentes con sus convicciones" (Sambrizzi, 2020, p. 1).

A estas alturas, la objeción de conciencia cuenta con una larga tradición; no obstante, en las últimas décadas ha tenido una importante expansión. Este proceso, que -probablemente por su intensidad- ha sido descripto como un "big bang jurídico" (Navarro-Valls y Martínez Torrón, 2012, p. 29, 31 y ss.) obedece a diversas causas.

Un tiempo atrás, Navarro Floria (2004) identificaba los factores que coadyuvaron a su "eclosión": en primer lugar, la tendencia a la "protección jurídica eficaz de los derechos humanos" en el ámbito internacional y su correlativo desarrollo en los países que adoptan sistemas democráticos. Luego, la "creciente (...)

(8) Nos concentraremos en la objeción de conciencia individual prevista por la ley 27.610 y su reglamentación. Un trabajo exhaustivo -en el que se examina el articulado de la ley de aborto completo- fue elaborado por Lafferriere (2021b). Añadiremos algunas referencias al Protocolo 2021, sin explayarnos demasiado: dicho instructivo ameritaría un análisis extenso; por otra parte, su vigencia es "acotada": las provincias, si quieren implementarlo, deben incorporarlo a su ordenamiento local (Lafferriere, 2021c, p. 1).

(9) Ciertamente, la “... objeción [de conciencia] es moral en su origen y jurídica en su expresión, no es lo mismo que la resistencia a la autoridad ni persigue una reacción social..." (Padilla, 2018, p. 2).

(10) George (2016a) compara la concepción de la libertad de conciencia de John Stuart Mill con la de John Henry Newman. El autor, que se inclina por el pensamiento del último, indica que "la conciencia tiene derechos porque tiene deberes" ( $p .117$; la traducción nos pertenece). La justificación de la libertad de conciencia sobre la base de un criterio exclusivamente voluntarista implica una deformación del concepto: podría haber tantas objeciones como deseos existan.

84 | Ediciones SAIJ < Ministerio de Justicia y Derechos Humanos de la Nación 
pluralidad religiosa e ideológica” en las comunidades, así como la imposición de un "cierto relativismo ético" que condujo a poner en duda instituciones otrora "indiscutibles" (pp. 26-27). Sin ir más lejos, ¿̇quién hubiera podido predecir la rapidez con la cual se introdujo el aborto a voluntad en nuestro ordenamiento jurídico que, desde siempre, sostuvo la protección de la vida desde la concepción? Por último, el autor referido señalaba, como uno de los factores que impulsaron la objeción de conciencia, la propensión de los Estados a favorecer políticas en determinados ámbitos (entre los cuales mencionaba el de la "salud pública") en forma compulsiva, a pesar del rechazo que provocan entre los miembros de la sociedad (Navarro Floria, 2004, pp. 26-27).

La multiplicidad de "objeciones de conciencia"(11) -particularmente, la repetición de casos de objeción individuales pero análogos respecto de un deber puntual- propició un cambio en el modo de su tratamiento legal. Otra vez, Navarro Floria (2004) explicaba que hoy "las legislaciones de los estados democráticos acogen la posibilidad de que los objetores de conciencia, en los casos en que la objeción es reglada, encuentren en la propia ley una vía de escape” (p. 40).

Esta evolución ha dado lugar a una clasificación o distinción entre dos "formas" de objeción de conciencia: propia o impropia. Habrá objeción de conciencia en sentido propio cuando el objetor actúe directamente contra la norma positiva y se arriesgue a soportar las consecuencias de su desobediencia; en cambio, la objeción de conciencia será "impropia" o "legalizada" si se obra según lo previsto por una ley que la admite expresamente (Navarro Floria, 2004, pp. 36-37 y 40-41). ${ }^{(12)}$

Como vemos, bajo el paraguas de la objeción de conciencia quedan subsumidos supuestos variopintos. En esta línea, se ha formulado otro distingo (Sambrizzi, 2021, p. 2), ${ }^{(13)}$ que bien podría dar lugar a una nueva clasificación. A veces se invoca la objeción de conciencia como medio de resguardo de la libertad del objetor, pero no se apunta a la invalidez de la norma que dispone el deber jurídico; estos planteos admiten las "prestaciones sustitutorias", ${ }^{14)}$ siempre y cuando la eximición de cumplimiento no cause perjuicios graves al bien común. En otros

(11) La expresión es de Navarro Floria (2004, p. 27) y de Navarro-Valls y Martínez Torrón (2012, p. 29).

(12) En el derecho comparado es común la expresión "cláusula de conciencia" [conscience clause]: "[l]a objeción de conciencia no debe confundirse con la cláusula de conciencia (...) la cláusula de conciencia contiene regulaciones que principalmente limitan la libertad de conciencia o religión (limitando también la objeción de conciencia) en consideración de otros valores importantes, como la seguridad y el orden público o la vida o la salud de un paciente" (Pawlikowski, 2019, p. 66; la traducción nos pertenece).

(13) Según afirma Sambrizzi (2021), es posible ejercer la objeción de conciencia contra una ley "incuestionable en sí misma (...) pero que hiera la conciencia del objetor". Para explicarse recurre al caso de una persona que rehúye de la realización del servicio militar con armas y agrega que algo similar ocurre con aquellos que, por su pertenencia al culto de los Testigos de Jehová, se niegan a prestar el juramento a la bandera. Como sea, para el autor, frente a una norma injusta o inmoral, "el ejercicio del derecho es todavía más claro" (p. 2).

(14) Navarro Floria (2004) refiere que las "prestaciones sustitutorias" procuran mantener la "igualdad"; aunque admite que, en determinados supuestos, son prescindibles: por ejemplo, el caso del médico frente al aborto (p. 39). 
casos, en cambio, la objeción de conciencia se fundamenta en la injusticia de la norma positiva, ${ }^{(15)}$ lo cual presupone el reconocimiento de que ninguna ley es (ni puede ser) neutral. ${ }^{16)}$ Estos últimos, cada vez más frecuentes, se enlazan con la visión clásica de la objeción de conciencia, comprendida como una reacción frente a la norma inicua. ${ }^{(17)}$

Naturalmente, la situación del objetor frente a la norma vigente, aunque injusta, produce tensiones sociales graves. Por un lado, descubre la finalidad torcida de la ley (de allí la antipatía que despierta entre los propulsores de la norma cuestionada). ${ }^{(18)}$ Por el otro, estos planteos de conciencia difícilmente admitan "prestaciones sustitutorias", pues no es razonable exigirle al objetor su cooperación con la consecución exitosa del acto objetado. La expansión de estas objeciones necesariamente llama a repensar los criterios para su reconocimiento. ${ }^{(19)}$

Si ponemos la lupa en la objeción de conciencia del personal sanitario, vemos que implica la posibilidad de excluirse de participar de un procedimiento que -en conciencia- juzgan inaceptable, aunque no exista en sentido estricto un "deber" legal de intervenir. Volveremos sobre este aspecto más adelante. Por ahora, basta con apuntar que, en su inmensa mayoría, las objeciones de conciencia de los trabajadores del área de la salud se relacionan con la permisión

(15) Santo Tomás de Aquino abordó la cuestión de la obligatoriedad de la ley humana en el foro de la conciencia y contempló -con una mirada realista de la vida social- que las leyes humanas podían ser injustas de dos modos: por oposición al bien humano o por oposición al bien divino. Las primeras por quebrantar el fin de la ley, por el autor o por imponer a los ciudadanos cargas desiguales; en estos casos, no obligan al súbdito en conciencia, salvo "que se trate de evitar el escándalo o desorden". Las leyes opuestas al bien divino, por el contrario, "nunca es lícito cumplirlas" (De Aquino, 1993, I- II, q. 96, a. 4).

(16) '[L]as leyes habitualmente llamadas 'neutrales' no son tan neutrales (...) no debemos olvidar que toda norma tiene un fundamento ético más o menos visible (...)" (Navarro-Valls y Martínez Torrón, 2012, p. 43).

(17) Por eso, se insiste en la necesidad de redescubrir la fundamentación iusnaturalista de la desobediencia civil (y también de la objeción de conciencia) (Portela, 2006, pp. 343- 345).

(18) En sentido similar véase Puppinck (2020, p. 232). La desconfianza hacia la objeción de conciencia se vislumbra, por ejemplo, en los planteos de NeJaime y Siegel (2020, pp. 8-9), que trazan un vínculo entre los reclamos de los objetores y las llamadas "guerras culturales".

(19) Didier (2015) analiza el principio de razonabilidad como criterio de interpretación para la valoración de la objeción de conciencia en el caso concreto. Desarrolla, así, los tres juicios que lo integran: adecuación, necesidad y proporcionalidad "en sentido estricto", a los cuales agrega un cuarto denominado "juicio de afectación o alteración del contenido esencial". Respecto de este último, resulta relevante su exploración dirigida a superar los criterios utilitaristas, mediante la "garantía de la inalterabilidad de los derechos fundamentales" (art. 28 CN). Justamente, Didier resalta la inconveniencia de comprender el derecho de objeción de conciencia únicamente desde la autonomía individual: “... en tanto la autonomía del objetor se enfrentará a la autonomía del tercero en beneficio del cual el deber objetado fue establecido, "[no] resultando factible determinar hasta dónde llega la autonomía de uno y otro ante la ausencia de criterios materiales". Luego, en sintonía con Finnis, esboza pautas a partir de una consideración de los "bienes humanos básicos" que la objeción de conciencia protege (Didier, 2015, p. 266). La propuesta es valiosa, porque apunta a la esencia del derecho y repara en los riesgos que acarrea un análisis reductivo -asentado en la mera autonomía- que amenaza con desfigurarlo. Por nuestra parte, adicionamos que la definición de los "bienes humanos básicos" exige una definición sobre la naturaleza humana. 
legal de técnicas o prácticas optativas, cuestionadas por su finalidad, como ocurre respecto del aborto voluntario.(20) Es notable que la "objeción de conciencia legalizada"(21) se haya vuelto común en las ciencias médicas: abundan las normas que, al tiempo que regulan un procedimiento, permiten que los profesionales de salud se evadan de su realización por razones de conciencia.

\section{La objeción de conciencia frente al aborto en el ordenamiento jurídico argentino}

Según el art. 10 de la ley 27.610, el profesional que deba "intervenir de manera directa en la interrupción del embarazo" tiene derecho a la objeción de conciencia. Su ejercicio está condicionado al cumplimiento de los requisitos allí enunciados, a saber:

a) que mantenga la decisión "en todos los ámbitos, público, privado o de la seguridad social" en donde desarrolle su trabajo;

b) que derive "de buena fe" a la mujer para que sea atendida "en forma temporánea y oportuna, sin dilaciones"; y

c) que cumpla con "el resto de sus deberes profesionales y obligaciones jurídicas".

Se establece, asimismo, que el objetor no puede negarse a realizar un aborto "en caso de que la vida o salud de la persona gestante esté en peligro y requiera atención inmediata e impostergable" y que tampoco podrá "alegar objeción de conciencia" respecto de la "atención sanitaria postaborto". El texto culmina con una advertencia: “... [e]l incumplimiento de las obligaciones establecidas en el presente artículo dará lugar a las sanciones disciplinarias, administrativas, penales y civiles, según corresponda”."(22)

A continuación, el art. 11 prevé que los efectores de salud del subsector privado o de la seguridad social, que no cuenten con profesionales de la salud dispuestos, deben derivar a la paciente a otro "que realice efectivamente la prestación", ocuparse de las "gestiones y costos asociados a la derivación y el traslado de la paciente", que "quedarán a cargo del efector que realice la derivación".(23) De

(20) Pawlikowsky (2019) señala que, si bien pueden referir a otras prácticas, la cuestión de la objeción de conciencia de los profesionales de la salud se vincula, generalmente, con procedimientos referidos a la etapa inicial o final de la vida humana (pp. 68 - 69).

(21) La expresión pertenece a Navarro Floria (2004, pp. 40-42).

(22) Sobre la objeción de conciencia individual, la reglamentación aprobada por el decreto 516/2021 solo dice: "Artículo 10.- Objeción de conciencia. De conformidad con el segundo párrafo del artículo 10 de la Ley № 27.610, el personal de salud no podrá negarse a la realización de la interrupción del embarazo en caso de emergencia, cuando la práctica deba realizarse en forma urgente pues su no realización inmediata pondría en riesgo la salud física o la vida de la persona gestante".

(23) El art. 11 completo establece: "Objeción de conciencia. Obligaciones de los establecimientos de salud. Aquellos efectores de salud del subsector privado o de la seguridad social que no cuenten con profesionales para realizar la interrupción del embarazo a causa del ejercicio del 
este modo, con una serie de condicionamientos, la ley reduce el margen de acción de los objetores. Curiosamente, sus defensores proponen a la "interrupción del embarazo" como una "opción" liberadora para la mujer, pero no vacilan en recortar la libertad del médico que considera dicha práctica un mal. Este criterio se ha infundido en la norma en cuestión. ${ }^{(24)}$

Sin embargo, la objeción de conciencia emerge de normas de jerarquía superior que determinan su protección en nuestro ordenamiento jurídico y que amparan al personal sanitario frente a posiciones restrictivas. Ocurre que la ley 27.610 dispone un supuesto de "objeción de conciencia legalizada" o "impropia"; pero no descarta el ejercicio de la objeción de conciencia en sentido propio. No podría hacerlo: su fundamento no es legal, sino constitucional (y esencialmente de derecho natural).

En Argentina, la objeción de conciencia se deriva del derecho a la libertad de conciencia (art. 19 CN), de la libertad de asociación, del derecho de trabajar, de la libertad de profesar el culto (arts. 14 y $20 \mathrm{CN}$ ) y de la libertad religiosa (art. $19 \mathrm{CN}$ ). ${ }^{(25)}$ Desde 1994, la protección de la libertad de conciencia y de religión se ha reforzado con el reconocimiento de la jerarquía constitucional de ciertos tratados de derechos humanos, que rigen "en las condiciones de su vigencia", todos los cuales valoran positivamente esas libertades y prohíben la discriminación fundada en tales razones (art. 75, inc. 22, CN). ${ }^{(26)}$

derecho de objeción de conciencia de conformidad con el artículo anterior, deberán prever y disponer la derivación a un efector que realice efectivamente la prestación y que sea de similares características al que la persona solicitante de la prestación consultó. En todos los casos se debe garantizar la realización de la práctica conforme a las previsiones de la presente ley. Las gestiones y costos asociados a la derivación y el traslado de la paciente quedarán a cargo del efector que realice la derivación. Todas las derivaciones contempladas en este artículo deberán facturarse de acuerdo con la cobertura a favor del efector que realice la práctica". El decreto 516/2021 no reglamentó este artículo.

(24) El Protocolo 2021 acentúa esa tendencia restrictiva respecto de la objeción de conciencia (pp. 35-38).

(25) También se la considera comprendida en el art. 33 CN.

(26) La protección de la libertad de conciencia, pensamiento y religión surge de la Declaración Universal de Derechos Humanos (arts. $1^{\circ}$ y 18); la Declaración Americana de los Derechos y Deberes del Hombre (art. III); la Convención Americana de Derechos Humanos (art. 12). Esta última menciona expresamente un supuesto de exención fundado en "razones de conciencia". Así, junto con la prohibición de la esclavitud y servidumbre, aclara que "... [n] constituyen trabajo forzoso u obligatorio, para los efectos de este artículo: (...) b. el servicio militar y, en los países donde se admite exención por razones de conciencia, el servicio nacional que la ley establezca en lugar de aquel (...)" (art. 6.3.b; el resaltado nos pertenece); la libertad de conciencia y religión no puede ser suspendida ni siquiera en caso de caso de "guerra, de peligro público o de otra emergencia que amenace la independencia o seguridad del Estado parte" (art. 27.1 y 2), tampoco se admite la discriminación por motivos de "religión, opiniones políticas o de cualquier otra índole" (art. 1.1). El Pacto Internacional de Derechos Civiles y Políticos también protege la libertad de conciencia y religión (art. 18). En la Convención Internacional sobre la Eliminación de todas las Formas de Discriminación Racial se establece que "... los Estados partes se comprometen a (...) garantizar el derecho de toda persona a la igualdad ante la ley, sin distinción de raza, color y origen nacional o étnico (...) particularmente en el goce de los derechos siguientes: (...) vii) el derecho a la libertad de pensamiento, de conciencia y religión" (art. $5^{\circ}$ ). 
Además, diversas leyes protegen la libertad de conciencia del personal sanitario respecto de ciertas técnicas. Entre ellas, cabe mencionar la ley 25.673 (BO 22/11/2002)(27) de Creación del Programa Nacional de Salud Sexual y Procreación Responsable y su reglamentación. ${ }^{(28)}$ Precisamente, la ley 27.610 viene a insertarse en ese marco. ${ }^{(29)}$

A nivel jurisprudencial, la Corte Suprema ha contemplado el derecho a la objeción de conciencia, con argumentos y alcances distintos. ${ }^{(30)}$ Respecto de la situación de los médicos y el aborto, en "F. A. L. s/ medida autosatisfactiva", con criterio restrictivo, "exhortó" al dictado de protocolos de atención que dispusieran “... un adecuado sistema que permita al personal sanitario ejercer su derecho de objeción de conciencia sin que ello se traduzca en derivaciones o demoras que comprometan la atención de la requirente del servicio..." (CSJN, 2012, cons. 29). ${ }^{(31)}$

Las provincias, en uso de sus facultades, han resguardado el derecho a la objeción de conciencia. En 2008, San Luis aprobó una ley que garantiza a sus habitantes "el derecho fundamental a no actuar en contra de la propia conciencia personal","32) sujeta a ciertas limitaciones y al cumplimiento de "prestaciones sustitutivas", cuando correspondieran (cfr. arts. $1^{\circ}, 2^{\circ}, 3^{\circ}$ y $4^{\circ}$ ). Otras han incorporado la objeción de conciencia mediante la protección de supuestos específicos. ${ }^{(33)}$

(27) En lo que interesa, el art. 10 establece: "Las instituciones privadas de carácter confesional que brinden por sí o por terceros servicios de salud, podrán con fundamento en sus convicciones, exceptuarse del cumplimiento de lo dispuesto en el artículo $6^{\circ}$, inciso b), de la presente ley". El art. 6, inc. b, por su parte, dice que "... [a] demanda de los beneficiarios y sobre la base de estudios previos, prescribir y suministrar los métodos y elementos anticonceptivos que deberán ser de carácter reversible, no abortivos y transitorios, respetando los criterios o convicciones de los destinatarios, salvo contraindicación médica específica y previa información brindada sobre las ventajas y desventajas de los métodos naturales y aquellos aprobados por la ANMAT. Aceptándose además las prácticas denominadas ligadura de trompas de Falopio y ligadura de conductos deferentes o vasectomía, requeridas formalmente como método de planificación familiar y/o anticoncepción (...)"; este último párrafo fue añadido por la Ley 26.130 de Régimen para las Intervenciones de Contracepción Quirúrgica (BO 29/08/2006).

(28) Nos referimos al decreto del PEN 1282/2003 (BO 26/05/2003).

(29) Véase el art. 6ㅇ de la ley 27.610. En Infoleg.gob.ar, la ley 27.610 aparece entre las normas que modifican y actualizan a la ley 25.673. Esta información se puede verificar en: http://servicios. infoleg.gob.ar/infoleglnternet/verVinculos.do?modo=2\&id=79831

(30) Entre otros, ver: CSJN (Fallos: 312:496; 335:799).

(31) A continuación, la Corte Suprema (Fallos: 335:197) explicitó que: “... [a] tales efectos, deberá exigirse que la objeción sea manifestada en el momento de la implementación del protocolo o al inicio de las actividades en el establecimiento de salud correspondiente, de forma tal que toda institución que atienda a las situaciones aquí examinadas cuente con recursos humanos suficientes para garantizar, en forma permanente, el ejercicio de los derechos que la ley le confiere a las víctimas de violencia sexual" (recuérdese que la cuestión planteada en el caso versaba sobre la interpretación del art. 86, inc. 2 CP, hoy parcialmente modificado por la ley 27.610). Este criterio fue reiterado (casi en forma textual) en CSJN (Fallos: 338:556, cons. 33).

(32) Cfr. art. $1^{\circ}$ de la ley 1-0650-2008 de la provincia de San Luis.

(33) Un estudio de las normas provinciales sobre la objeción de conciencia puede verse en Cunha Ferré (2016). 


\section{Los fundamentos de la objeción de conciencia frente al aborto}

Sin duda, la objeción de conciencia frente al aborto encuentra sustento en nuestro derecho positivo. Pero existen motivos adicionales que -desde una perspectiva realista- agudizan la necesidad de preservar la libertad de conciencia de quienes se desempeñan en el ámbito de la salud. Nos detendremos en dos consideraciones, cuya enunciación constituye un buen punto de partida de cara a comprender la situación del médico objetor. A partir de dichas reflexiones, en el próximo acápite, formularemos observaciones críticas a la regulación de la objeción de conciencia de la ley 27.610 .

\subsection{La finalidad de la medicina}

La objeción de conciencia frente el aborto es generalmente aceptada en el derecho comparado y se encuentra presente -con mayor o menor amplitud- en la legislación de los países que propiciaron la despenalización o legalización del procedimiento. ${ }^{(34)}$ Incluso, en aquellos que fueron pioneros en la permisión de la práctica, a pesar de las décadas transcurridas, persisten los conflictos de conciencia entre los integrantes del personal sanitario. ${ }^{(35)}$

Las razones que justifican la objeción de conciencia no son caprichosas: no se trata de una cuestión individualista, relativista o de convención. Su fundamento último responde a los fines esenciales de la ciencia médica, orientada a cuidar de la vida humana en todas sus etapas.

Por mucho que intente eludirse con eufemismos, el aborto tiene como consecuencia buscada la destrucción de un ser humano no nacido. Empero, la deontología propia de las ciencias de la salud ordena al profesional a proteger toda vida humana; también la del niño por nacer, que es su paciente en la etapa gestacional. Es que el aborto -aunque requiere de cierta "pericia" para su realización- no puede ser considerado, propiamente, una práctica médica (Calderone et. al., 2020, p. 153); esta realidad ha llevado a decir que la objeción contra el aborto es "de ciencia" (y no exclusivamente de conciencia) (De Martini, 2012, p. 16):

En efecto, el aborto no es una terapia, ni un remedio, no tiene ninguna acción terapéutica. Más aún, lo que es decisivo desde un punto de vista jurídico, es que el aborto no

(34) Franck, Riccardi y Campo (2020) han demostrado que la cuestión de la objeción de conciencia representa un aspecto clave en los debates por la legalización del aborto en Occidente. Respecto de su protección formulan una clasificación: a) en los países que prohíben el aborto, los ordenamientos jurídicos reconocen la libertad de conciencia y de pensamiento en general y, simultáneamente, protegen la objeción de conciencia respecto de ciertos supuestos en particular; b) en los países que despenalizaron o legalizaron el aborto, salvo contadas excepciones, se ha reconocido la objeción de conciencia de los profesionales de la salud frente a la práctica, aunque con distintos alcances.

(35) Recientemente, algunas organizaciones que impulsan el acceso al procedimiento en Argentina publicaron un Mapa de normas sobre objeción de conciencia y aborto. De ese relevamiento surge que son escasos los ordenamientos jurídicos que prohíben el derecho de los objetores y que en los países en los cuales se legalizó la práctica (ya sea libre o por causales) suele estar reconocido (Ramón Michel et al., 2021). 
forma parte de la terapéutica. Ninguna relación tiene con la ciencia y el arte de curar. No forma parte de la currícula de ninguna materia de la Facultad de Medicina. Ningún médico hace su residencia practicando abortos.

Se dirá que el médico es el único profesional que sabe (o que podría saber) practicar abortos. Puede que así sea (en algunas especialidades, al menos). Pero el que sepa hacerlo no quiere decir que forme parte de su función profesional. (De Martini, 2012, p. 14)

Es esperable, entonces, que el personal sanitario se oponga a cooperar en un acto cuyo objetivo principal es acabar con el niño no nacido (y que no le reporta a la mujer beneficios en materia de salud). ${ }^{(36)}$ El accionar de los médicos -como la ley- no es moralmente neutro: como consecuencia, es habitual que los agentes sanitarios se rehúsen a colaborar con prácticas que atentan contra la vida humana, a pesar de que su actitud los expone a sufrir resultados desagradables: ya sea la discriminación laboral, sanciones disciplinarias o la pérdida del empleo.

En un estudio exploratorio, impulsado en Bogotá, se entrevistó a un grupo de médicos objetores para desentrañar las "... influencias éticas, morales, religiosas y legales en torno a la provisión y referencia de servicios de aborto" (Fink et al., 2017, p. 3). Una lectura atenta del trabajo sugiere que todos los profesionales consultados manifestaron la importancia de sus deberes médicos como fundamento para rechazar la práctica (Fink et al., 2017, pp. 5-7) y que, frente a ciertas circunstancias -en especial si la edad gestacional del nasciturus es muy avanzada-, las objeciones se intensifican. ${ }^{(37)}$

Las razones aducidas, ni más ni menos, apuntan al reconocimiento del niño por nacer como paciente, exponen la brutalidad del aborto y reivindican los objetivos de la ciencia médica. Como señala Puppinck (2020):

Si la cuestión del derecho a la objeción de conciencia está siendo tan disputada, es porque la conciencia personal es el último y verdadero testigo de la verdad y del bien. La objeción de conciencia es un testimonio, emana de un juicio sobre la realidad y la moralidad de un acto concreto. La legitimidad de una objeción de conciencia depende, por tanto, de la moralidad del acto contra el que se objeta. Una de dos: o bien ese acto es malo, y la objeción de conciencia contra este acto es justa, o bien el acto es bueno, y entonces es la objeción la que es injusta (p. 232).

Por ello, agrega, los promotores del aborto "se oponen tanto a la inserción de una cláusula de conciencia en la ley, porque esa cláusula implica reconocer que el acto por el que militan no es más que un mal tolerado" (Puppinck, 2020, p. 232).

(36) George (2016b) explica que el embarazo no es una enfermedad y que el aborto no obedece a razones de salud, sino que responde a los deseos de la mujer (p. 187).

(37) La investigación se dirige a comprender la objeción de conciencia de los médicos, considerada por los autores como "una barrera" para el acceso al aborto. El estudio permitió diferenciar tres "tipos de objeciones": extremas, moderadas y parciales (pp. 5-7). En fin, a pesar de que se orienta a favorecer la práctica entre los agentes de salud, las entrevistas arrojaron resultados ilustrativos: de las transcripciones de las respuestas de los profesionales se infiere la preocupación que les causa este tema. 
La legalización del aborto conmueve los cimientos del juramento hipocrático y coloca en dificultades a quienes realizaron esa promesa. ${ }^{(38)}$ Por eso, se ha apuntado que las conversaciones sobre la objeción de conciencia de los profesionales de la salud reclaman una reflexión acerca de la finalidad esencial de la medicina; solo a partir de esa definición será posible "... delinear los alcances, necesidad, oportunidad y justificación de los deberes impuestos a los trabajadores de la salud" (Pawlikowski, 2019, p. 67). ${ }^{(39)}$ Del mismo modo, se ha advertido la peligrosidad que supone el abandono de los límites de esta ciencia, anclados en el reconocimiento de la dignidad humana. ${ }^{(40)}$

En Argentina, además de las razones mencionadas, la convicción de que el niño no nacido debe ser tratado como paciente encuentra sustento en el derecho vigente, ${ }^{(41)}$ pues -incluso con el aborto legal y aunque atemperada- persiste su protección desde la concepción. ${ }^{(42)}$

\subsection{La relación entre el médico y el paciente}

El trabajo en el consultorio exige que el profesional (sea o no objetor) cuente con un espacio adecuado para aconsejar con honestidad a quien se presenta como paciente. ${ }^{(43)}$ No es únicamente una cuestión facultativa para el médico, sino un verdadero deber.

Conviene tener presente que el personal sanitario no puede ser obligado a aplicar una práctica concreta respecto de un paciente determinado (De Martini, 2012, p. 15; De la Riva, 2019, p. 3), sino que evalúa cada situación en particular y emite una recomendación o consejo. ${ }^{(44)}$ Esto es especialmente cierto frente

(38) Véase la Declaración de Ginebra, adoptada por la 2a Asamblea General de la Asociación Médica Mundial, en Ginebra, Suiza, en septiembre de 1948. La versión actual, con las enmiendas de 1968, 1983, 1994, 2005, 2006 y 2017, se encuentra en: https://www.wma.net/es/policies-post/ declaracion-de-ginebra/

(39) La traducción nos pertenece.

(40) Puppinck (2020) recuerda que: “... [I]a medicina debía limitarse a 'curar', ese era su límite por respeto a la dignidad humana y sus corolarios: principios de indisponibilidad y de inviolabilidad del cuerpo humano. Este límite también ha sido eliminado en estos últimos decenios, como la mayor parte de los que descansaban en una concepción de la dignidad basada en la naturaleza humana” (p. 207).

(41) En verdad, “... la disyuntiva moral del médico frente al aborto es especialmente atendible a la luz de nuestro ordenamiento jurídico que protege al niño desde la concepción" (Calderone et al., 2020, p. 169).

(42) Entre otras, se destacan el art. 75, incs. 22 y 23 CN, la ley 23.849 que aprueba la Convención sobre los Derechos del Niño (BO, 22/10/1990); el art. 19 del Código Civil y Comercial de la Nación (BO 08/10/2014) y el art. 85 y ss. del Código Penal que, como señalamos, mantiene tipificado el aborto. Un análisis detallado de la protección de la vida no nacida en nuestro derecho y la contradicción de la ley 27.610 con normas de jerarquía superior puede verse en García Mansilla (2021)

(43) La ley 17.132 (BO, 31/01/1967) prohíbe a los profesionales que ejercen la medicina "... prometer el alivio o la curación por medio de procedimientos secretos o misteriosos” (art. 20, inc. 3).

(44) "[S]i, además, analizamos la cuestión desde la perspectiva de la relación médico-paciente, parece claro que el paciente no es el que indica el tratamiento a seguir y, mucho menos, puede exigirlo (...) El médico tiene siempre la libertad de proponer el tratamiento más adecuado para 
a procedimientos que, como el aborto, dependen de la voluntad de la solicitante ${ }^{(45)}$ y que admiten soluciones alternativas. Desde luego que el médico no puede rechazar a la mujer que le "exige" interrumpir su embarazo -quien merece ser tratada dignamente-, más no tiene por qué obrar como ella le pide (Calderone et al., 2020, p. 165).(46)

Como contracara, el paciente -cualquiera sea su dolencia- tiene derecho a recibir información precisa sobre todos los medicamentos, procedimientos o tratamientos disponibles y sus efectos; de hecho, dicha información (y su comprensión) es fundamental para recabar el consentimiento informado. ${ }^{(47)}$ Es paradojal que se sostenga que el aborto es una decisión autónoma de la mujer, pero que a su vez se pretenda restringirle el acceso a datos cruciales en el momento de la resolución. ${ }^{(48)}$ Cabe preguntarse, si se oculta deliberadamente información relevante, ¿se garantiza la libertad de elección? Sin quererlo, la negativa de los agentes de salud a colaborar con el aborto se presenta como una última oportunidad para que la paciente tome otro camino.

De cualquier modo, como la autonomía no puede ser el único parámetro para proteger a la conciencia (Didier, 2016, p. 266), tampoco es suficiente para definir las relaciones en la clínica (Pellegrino, 1990):(49) el conocimiento del profe-

hacer frente a la dolencia o enfermedad. De ahí que nunca pueda ser obligado, ni exigido de ningún modo, a practicar una terapia determinada" (De Martini, 2012, p. 15).

(45) El aborto voluntario es "una decisión basada en consideraciones que no son médicas [nonmedical considerations]” (George, 2016b, p. 186; la traducción nos pertenece).

(46) La objeción de conciencia no significa "el rechazo de la persona y el abandono del paciente" (Academia Nacional de Medicina, 2000).

(47) En nuestro país, está regulado por la ley 26.529 (BO, 20/11/2009) y su modificatoria (ley 26.742, BO 24/05/2012) y por el art. 59 del Código Civil y Comercial de la Nación (BO, 08/10/2014).

(48) La Corte Interamericana de Derechos Humanos (en adelante, Corte IDH) consideró los requisitos del consentimiento informado en "I. V. vs. Bolivia" (2016). La peticionaria, una mujer inmigrante, denunció que luego de que se le practicara una cesárea, le habían realizado la ligadura de trompas de Falopio sin su consentimiento. En ese contexto, el tribunal determinó que el consentimiento es un "prerequisito" de los actos médicos y que debe ser: i) previo; ii) libre; iii) pleno e informado (párrs. 170-196). Dijo, asimismo que “... [m]ientras mayores sean las consecuencias de la decisión que se va a adoptar, más rigurosos deberán ser los controles para asegurar que un consentimiento válido sea realmente otorgado" (párr. 196). Si bien no podemos tomar todas las elaboraciones de la Corte IDH sin beneficio de inventario (y sin olvidar que Argentina no fue parte en el caso), estimamos valioso que detallara el procedimiento para recabar el consentimiento, como un mecanismo para evitar posibles abusos. En suma, la Corte IDH indicó que, para que exista consentimiento pleno los prestadores de salud deben informar a su paciente sobre: "i) la evaluación de diagnóstico; ii) el objetivo, método, duración probable, beneficios y riesgos esperados del tratamiento propuesto; iii) los posibles efectos desfavorables del tratamiento propuesto; iv) las alternativas de tratamiento, incluyendo aquellas menos intrusivas, y el posible dolor o malestar, riesgos, beneficios y efectos secundarios del tratamiento alternativo propuesto; v) las consecuencias de los tratamientos, y vi) lo que se estima ocurrirá antes, durante y después del tratamiento" (párr. 189) y que "... de existir alternativas de tratamiento, dicha información forma parte del concepto de información necesaria para adoptar un consentimiento informado y su impartición se considera como un elemento básico de dicho consentimiento" (párr. 190). Estos estándares podrían aplicarse al caso del aborto.

(49) Pellegrino (1990) ha argumentado que la sola autonomía presenta serias "deficiencias" en la definición de la relación entre el médico y el paciente. Así, indicaba que la absolutización de 
sional no puede quedar subordinado al mero deseo del paciente ni prescindir de los objetivos propios de la ciencia médica. En esa tesitura, Sartea (2016) urge a repensar los términos de dicho vínculo:

Así las cosas, para que sea posible un diálogo -clínico y jurídico, además que humano y moral- entre paciente y médico, es indispensable que ambos acepten un horizonte de referencia común, que es el mismo que justifica la necesidad del paciente (causa de su dirigirse al médico, es decir, origen primero, existencial y fáctico, de la relación) y el involucramiento del médico (escogido por sus competencias y habilidades específicas, como profesional del sector). Ese punto de contacto del que depende la misma posibilidad del diálogo no puede ser sino la salud de la persona humana, pero una salud necesariamente pensada de forma objetiva y no solamente subjetiva: aunque en su mismo concepto haya que incluir también los elementos de bienestar psicológico y espiritual del paciente y de su entorno. De otra forma, el abandono de la objetividad implicaría la pérdida del sentido mismo de la profesionalidad y la corrupción insanable de la relación clínica. (p. 142)

\section{Observaciones críticas a la regulación de la objeción de conciencia en la ley 27.610}

Enfoquémonos, nuevamente, en la regulación de la objeción de conciencia de la ley 27.610. A estas alturas, es obvio que las cláusulas allí contenidas plantean algunos conflictos jurídicos. En rigor, el defecto principal de la ley estriba en que concibe al aborto como una práctica médica -o peor, un "derecho" de la mujera pesar de que no contribuye a su salud (tampoco a la salud pública, que parece haber relegado el cuidado de la vida prenatal). Esa premisa errada conlleva la imposición de cargas muy pesadas a los agentes sanitarios y el retaceo del ámbito de acción de los objetores.

Pero nuestro ordenamiento jurídico admite un amplio resguardo de la objeción de conciencia del médico frente al aborto. De un lado, porque consagra la libertad de conciencia y de religión como derechos constitucionales. Del otro, porque protege al niño desde la concepción: es decir, valida la convicción de que el ser humano por nacer es un paciente y que no puede ser eliminado sin más. En esa línea, resultan incomprensibles las limitaciones dispuestas a la objeción de conciencia por cuanto "alteran" el contenido de ese derecho. ${ }^{(50)}$ Veamos.

Primero. Si el profesional de la salud objeta el aborto, porque se niega a contribuir con su saber en la muerte a un ser humano inocente, no puede ayudar a que se realice la práctica de ningún modo; de allí que sea forzoso reconocerle este derecho a todos los miembros del personal sanitario que estén llamados

\footnotetext{
la autonomía, primero, tiende a una visión "legalista" de esa relación, que "fomenta la ficción de que puede existir un contrato", a pesar de la situación de vulnerabilidad que enfrenta el paciente; segundo, "minimiza las obligaciones del médico respecto a la beneficencia y a la renuncia al propio interés" y, tercero, provoca "un culto de privatismo moral, atomismo e individualismo insensible al hecho de que los seres humanos son miembros de una comunidad moral". Como solución, invita a reconsiderar la relación entre el médico y el paciente sobre la base del concepto de "integridad" (pp. 382- 383).
}

(50) El art. 28 CN establece: "Los principios, garantías y derechos reconocidos en los anteriores artículos, no podrán ser alterados por las leyes que reglamenten su ejercicio". 
a participar, sin discriminación (art. $16 \mathrm{CN}$ ). Al mismo tiempo, el concepto de "intervención directa" (cfr. art. 10 de la ley 27.160) debe interpretarse en sentido amplio y solo podrá ser apreciado prudencialmente en el caso concreto. ${ }^{(51)}$ La ley 27.610 (y también el Protocolo 2021) distribuye los "deberes" de la provisión del aborto entre especialistas de distintas disciplinas porque el proceso exige la mediación de múltiples actores. Todos, consecuentemente, tienen derecho a declararse objetores en tanto su aporte sea "necesario" para su consecución. ${ }^{(52)}$ Tomemos un ejemplo: el Protocolo 2021 supone que la realización de una ecografía no podría acarrear problemas de conciencia para un objetor porque "no tiene por finalidad interrumpir la gestación", es complementario respecto de diversos procedimientos (p. 35) y no es "un estudio de rutina" para el aborto en particular (p. 57). Ahora bien, una lectura atenta del instructivo permite comprobar -como lo indica el sentido común- que la ecografía es relevante en relación con el procedimiento abortivo. Este estudio es decisivo para confirmar el embarazo, asegurar que no es ectópico y también para conocer la edad gestacional (p. 57). Más todavía, el Protocolo 2021 fija una serie de "precauciones" especiales, dirigidas al técnico ecógrafo encargado de la ecografía previa al aborto. Así, se exige que le explique a la paciente "su derecho a solicitar no ver las imágenes ni escuchar los sonidos" y que "[e]n caso de realizarse la ecografía, solo se compartirán con la persona la imagen o el sonido de los latidos si ella lo solicita expresamente. Si no lo hace, es de suma importancia tomar los recaudos necesarios para que esto no suceda" (p. 57). De manera que no es inocua la intervención del profesional que manipula el ecógrafo, sino que su tarea lo involucra en una cooperación directa (y activa) con el aborto. Muy distinto es que una mujer se presente al consultorio dubitativa y que pida una ecografía para ver al niño que crece en su vientre. Como vemos, no pueden fijarse criterios taxativos y estáticos que desconozcan las vicisitudes y contingencias de la práctica médica y de las conductas humanas. Por esa razón, consideramos que la determinación acerca de qué es "intervención directa" corresponde, en principio, a cada profesional involucrado en el aborto y, en última instancia, al juez. ${ }^{(53)}$ En cualquier caso, los miembros del personal

(51) La referencia a la "intervención directa" (art. 10 de la ley 27.610) es, al decir de Lafferriere (2021b), "... poco feliz, pues podría querer interpretarse como limitando la objeción a algunos profesionales únicamente. En realidad, todos aquellos que de alguna forma participan de un aborto pueden ser objetores a tenor de las normas antes invocadas y de otras disposiciones (enfermeras y enfermeros, genetistas, ecografistas, farmacéuticos, instrumentistas, trabajadores sociales, etc.). En este sentido, así como el art. 19 señala que todo el personal de salud se ha de capacitar sobre el aborto, también todo el personal de salud debería poder ser objetor" (p. 112).

(52) El personal sanitario que se desempeña en el Estado también tiene derecho a manifestar su objeción frente al aborto y no lo pierde por su condición de empleado público (De la Riva, 2019).

(53) Dice el Protocolo 2021 que la “... objeción puede ser invocada respecto a realizar la práctica concreta (intervención directa) de la IVE/ILE, pero no para las acciones necesarias para garantizar la atención integral de la salud (...) sean previas o posteriores a la interrupción (por ejemplo: realización de ecografías, toma de tensión arterial o la temperatura, seguimiento post aborto, entre otras)" (p. 35). No se nos escapa que el instructivo contiene una interpretación excesiva 
sanitario siempre podrán ejercer el derecho a la objeción de conciencia en sentido propio (esto es, no legislada).

Segundo. Tampoco es sensato obligar al objetor a derivar en forma efectiva, pues ese acto importa, como señala Lafferriere (2021b), "una forma de cooperación con la acción objetada" (p. 112). ${ }^{(54)}$ El Protocolo 2021 es ilustrativo en este punto porque explicita la activa intervención que requiere la derivación "de buena fe" y en qué medida contribuye a la consumación de la práctica. Según dicho instructivo, el objetor debe entregar información sobre el procedimiento y después derivar a otro profesional que, en su opinión, "esté capacitado (...), disponible y pueda realizar la práctica en un tiempo clínicamente razonable"; además, al objetor le cabe "realizar los arreglos" para que se produzca el aborto ("y [que] se lleve a cabo por (...) el profesional al que fue derivada" la paciente). También se le encarga "considerar los mecanismos de derivación y atención en acuerdo con la gestante para que no supongan cargas injustificadas" (p. 36). ${ }^{(55)}$ Entendemos que el médico podrá negarse a la derivación directa porque, como se explicó, lo fuerza a colaborar con el acto rechazado; se tratará de un caso de objeción de conciencia en sentido propio. ${ }^{(56)}$

Tercero. La obligación de intervenir en el aborto cuando "la vida o salud de la persona gestante esté en peligro y requiera atención inmediata e impostergable" es ambigua. ${ }^{(57)}$ Ningún médico puede negarse a asistir a un paciente, pero eso no supone que pueda imponérsele qué procedimiento debe realizar (De Martini, 2012, pp. 15-16); menos si la práctica que se le exige es voluntaria (recuérdese que hasta la semana 14 inclusive no hace falta la invocación de una causal para la solicitud). En el estado actual de la ciencia, dado que el aborto no es una técnica curativa, cuesta creer que sea el único modo para resolver el problema de una paciente. Lafferriere (2021b) explica que la norma "confunde situaciones diferentes":

En realidad, si hay una situación de peligro inminente e inevitable, que requiere una acción terapéutica hacia la madre que tiene como efecto secundario no deseado la muerte del por nacer, y no hay otras alternativas terapéuticas, el objetor actuaría como todo profesional para salvar la vida. En cambio, si la norma pretende que se obligue a un profesional a realizar un aborto directo, ello contraviene las convicciones personales y los derechos fundamentales. (2021b, p. 113)

de la ley en este punto y tampoco que el Ministerio de Salud no se encuentra facultado para regular (menos restringir) derechos.

(54) En igual sentido se pronuncia Sambrizzi (2021, p. 2).

(55) El Protocolo 2021 -en un cuestionable exceso- acentúa la obligación de intervenir del profesional objetor también cuando "... no existiera un/a profesional disponible para la realizar la práctica de forma oportuna, tal y como lo establece el artículo 10 de la Ley 27.610, el artículo 2.a de la Ley 26529 y artículo 19.2 de la Ley 17132" (p. 36 y 38).

(56) Lo indicado respecto del deber de derivar se aplica al profesional que se desempeña en una institución de ideario en la que no se hacen abortos. Como afirma Toller (2007), el derecho a la libertad de conciencia del personal sanitario se "trasvasa o proyecta" a la asociación prestadora de salud que integra (p. 168).

(57) La ambigüedad se mantiene en la reglamentación del decreto 516/2021. 
Cuarto. Otro tanto debemos que decir de la imposibilidad de objetar la atención posaborto. Nos encontramos aquí ante una nueva obligación ambivalente: por empezar, la norma no define qué debe entenderse por tal, lo que podría dar lugar a interpretaciones que avancen sobre la conciencia de los agentes sanitarios. Por su parte, el médico nunca puede abandonar a la embarazada si su vida peligra, pero si la situación que atraviesa la mujer es reversible (y el niño por nacer no ha muerto) no puede obligarse al objetor a continuar un aborto que no comenzó. Forzarlo a intervenir en estas circunstancias, sobre todo si el embarazo puede salvarse, no es sino una interpretación abusiva y oportunista de la ley. ${ }^{(58)}$ Corresponderá, entonces, a los miembros del personal sanitario evaluar la situación concreta; sin perjuicio de lo cual, resaltamos, son los servicios de salud los que deberán organizar la atención de estos pedidos de modo que se respete a quienes declararon su objeción.

Quinto. Las cargas impuestas a los profesionales de la salud(59) (independientemente de su condición de objetores) -ya sea para que realicen el aborto sin dilación, para que callen sobre sus consecuencias o para evitar que le ofrezcan alternativas a la mujer-(60) ${ }^{(60}$ savan (y hasta lastiman) la relación entre el médico y su paciente, justo cuando necesita sanar. Lamentablemente, la ley de aborto trasluce una visión, a nuestro juicio, equivocada de la medicina: propone una suerte de enfrentamiento entre el personal sanitario y quien se presenta requiriéndole su ayuda. Los mecanismos de presión, legitimados por la norma, quiebran la relación de confianza que debe primar en la consulta médica, en es-

(58) El proceso del aborto medicamentoso no es inmediato; muchas veces quien prescribe la droga ya no se encuentra en la clínica cuando se desencadenan las contracciones y el sangrado. Aquí se pone sobre la mesa el problema de la responsabilidad del profesional que lo inició, quien debería hacer el seguimiento hasta el fin del procedimiento. Estimamos que esta cuestión merece su propio desarrollo, que excede esta investigación.

(59) Resulta particularmente grave la introducción del delito contenido en el nuevo art. 85 bis del Código Penal, que dice: "Será reprimido o reprimida con prisión de tres (3) meses a un (1) año e inhabilitación especial por el doble del tiempo de la condena, el funcionario público o la funcionaria pública o la autoridad del establecimiento de salud, profesional, efector o personal de salud que dilatare injustificadamente, obstaculizare o se negare, en contravención de la normativa vigente, a practicar un aborto en los casos legalmente autorizados" (cfr. art. 15 de la ley 27.610). Munilla Lacasa (2021) señala que es poco razonable imponer semejante amenaza a los profesionales de la salud, que no existen figuras delictivas de este tenor en el derecho comparado y que, en última instancia, representa una "monumental embestida contra la objeción de conciencia y contra la libertad de ejercicio profesional” (p. 8). Respecto de sus caracteres, explica que la acción típica presenta ciertas "imprecisiones dogmáticas" porque el legislador no ha definido cuándo la dilación será "injustificada”, ni tampoco quién o bajo qué criterios debe determinase. Dicha circunstancia, concluye, deberá valorarse "en el marco de un proceso judicial”. Por otra parte, especifica que "... la flamante disposición es de acción pública; es de pura actividad (no requiere un resultado y no admite tentativa); es dolosa (admite dolo eventual); es un delito especial propio, pues solo puede ser cometido por los sujetos activos indicados; es instantáneo para el caso de la acción típica de 'negarse', pero permanente para las restantes dos acciones: 'dilatare' y 'obstaculizare'” (Munilla Lacasa, 2021, p. 7).

(60) Debe notarse que el art. $5^{\circ}$, inc. $\mathrm{d}$, de la ley 27.610 dispone: “... [e]l personal de salud debe respetar las decisiones de las pacientes respecto al ejercicio de sus derechos reproductivos, las alternativas de tratamiento y su futura salud sexual y reproductiva. Las decisiones de la paciente no deben ser sometidas a juicios derivados de consideraciones personales, religiosas o axiológicas por parte del personal de salud, debiendo prevalecer su libre y autónoma voluntad". 
pecial si, como suele ocurrir con las embarazadas que se enfrentan a la decisión de un aborto, la paciente se encuentra en un estado de vulnerabilidad tal que le impide apreciar la situación con objetividad.

\section{Conclusiones}

La permisión laxa del aborto en Argentina presenta serios problemas. Uno de los conflictos más álgidos refiere a los dilemas de conciencia que la práctica provoca en el personal sanitario. La ley 27.610 se hace eco de las disyuntivas morales que ocasiona un procedimiento cuyo objeto es suprimir una vida humana y prevé la objeción de conciencia (arts. 10 y 11). Desafortunadamente, ha adoptado un criterio irrazonable en cuanto desnaturaliza el derecho que pretende resguardar.

Consideramos, en todo caso, que se trata de una "objeción de conciencia legislada" o impropia (Navarro Floria, 2004, p. 40- 42), que no descarta el ejercicio de la objeción de conciencia en sentido propio, derivada del derecho natural, de la libertad de conciencia, de culto y de asociación, todas consagradas en la Constitución Nacional. Su fundamento último es objetivo e incuestionable: la deontología de la ciencia médica y la índole de la relación entre el profesional y su paciente, que debe ordenarse a la sanación (Sartea, 2016, p. 142).

Damos por descontado que la ley de aborto dará lugar a innumerables debates y conflictos (García Mansilla, 2021). Algunos ya se vislumbran, otros están por venir, unos tantos se judicializarán. Nos aventuramos a afirmar que la estrechez de la objeción de conciencia será uno de los grandes puntos de discusión.

En este panorama, tantas veces desalentador, queda mucho por hacer. Sabemos que el reconocimiento de la objeción de conciencia no es suficiente, no resuelve la injusticia de la legalización del aborto, ${ }^{(61)}$ no protege de la vida del niño por nacer (ni siquiera soluciona el problema de las mujeres que atraviesan las dificultades de un embarazo inesperado). Pero, por ahora, la conciencia del médico es, quizás, la única esperanza para quienes se enfrentan a la terrible situación del aborto y un buen recordatorio de la finalidad de la medicina.

\section{Referencias bibliográficas}

Academia Nacional de Medicina. (2000). Declaración de la Academia Nacional de Medicina sobre objeción de conciencia. https://anm.edu.ar/declaraciones2/

Asociación Médica Mundial. (2017). Declaración de Ginebra. 2aㅗ Asamblea General de la AMM Ginebra, Suiza. https://www.wma.net/es/policies-post/declaracion-de-ginebra/

(61) En idéntico sentido, se afirma que "la objeción de conciencia funciona como una última frontera (alguno dirá, como un triste premio consuelo) frente a una ley injusta. Lo ideal sería que la ley sea justa y que proteja la vida humana y los derechos y dignidad de toda persona, en particular de los más débiles y vulnerables, en toda la extensión posible. Pero si por alguna razón el legislador opta por otro camino, lo mínimo que cabe exigirle es que al propio tiempo acepte este límite" (Navarro Floria, 2018). 
Calderone, S.; Agüero Ovejero, I.; Pereda, G. y Castellanos, G. (2020). La restricción de la objeción de conciencia de los profesionales de la salud al aborto: problemas jurídicos. Revista de Derecho de Familia y de las Personas (DFyP), (2), año XII, pp. 153- 169. Cita digital: AR/DOC/681/2020.

Cunha Ferré, M. M. (2016). Mapa normativo de la objeción de conciencia en la República Argentina. El Derecho, tomo 269, pp. 1-6. Cita digital: ED-DCCLXXVI-218.

Costa, J. M. (18 de febrero de 2021). General Viamonte: renunció el secretario de Salud en oposición a la ley del aborto. La Nación. https://www.lanacion.com.ar/sociedad/general-viamonte-renuncio-el-secretario-de-salud-por-que-se-opone-a-la-ley-del-aborto-nid18022021/

De Martini, S. M. Á. (2012). Ni los médicos, ni los centros de salud, están jurídicamente obligados a practicar abortos. En AAVV, El médico frente al aborto (pp. 5-18). Educa. https://repositorio.uca.edu.ar/bitstream/123456789/8538/1/medico-frente-aborto-demartini.pdf

De la Riva, I. M. (2019). La objeción de conciencia de los médicos en los hospitales públicos. El Derecho, tomo 285. Cita digital: ED-CMVII-825.

Didier, M. M. (2015). El derecho a la objeción de conciencia: criterios para su interpretación. Díkaion, 24(2), pp. 253-281. https://dikaion.unisabana.edu.co/index.php/dikaion/article/ view/5194

Franck, M. I.; Riccardi, M. S. y Campo, L. (2020). La objeción de conciencia frente al aborto en el derecho comparado. El Derecho, tomo 286. Cita digital: ED-CMXIII-235.

Fink, L. R., Stanhope, K., Rochat, R. W., Bernal, O. A. (2017). "El feto también es mi paciente": Actitudes hacia el aborto y la referencia entre médicos objectores de conciencia en Bogotá, Colombia. Perspectivas Internacionales en Salud Sexual y Reproductiva, número especial, pp. 1-10. http://www.redaas.org.ar/archivos-recursos/471-42e1016sp.pdf

García-Mansilla, M. J. (2021). Inconstitucionalidad de la Ley 27.610. Temas de Derecho Penal y Procesal Penal. Erreius. Cita digital: IUSDC3288038A.

George, R. P. (2016a). Two concepts of liberty... and conscience. Conscience and its enemies: confronting the dogmas of liberal secularism. ISI Books/Intercollegiate Studies Institute.

(2016b). Conscience and its enemies. Conscience and its enemies: confronting the dogmas of liberal secularism. ISI Books/Intercollegiate Studies Institute.

Lafferriere, J. N. (2021a). Promulgada la ley 27.610 de aborto en Argentina con veto de una palabra. El Derecho - Diario, tomo 290. Cita digital: ED-MX-170.

(2021b). Ley de aborto comentada. Análisis crítico de la ley 27610. Centro de Bioética, Persona y Familia (libro electrónico). https://centrodebioetica.org/libro-electronico-ley-de-aborto-comentada-analisis-critico-de-la-ley-27610/

(2021c). Análisis del Protocolo de aborto (Res. 1535/2021 MSAL). Centro de Bioética Persona y Familia. https://centrodebioetica.org/analisis-del-protocolo-de-abortores-1535-2021-msal/

Munilla Lacasa, H. (2021). El nuevo delito del art. 85 bis del Código Penal. SJA. Cita digital: AR/DOC/853/2021. 
Navarro Floria, J. G. (2004). El derecho a la objeción de conciencia. Ábaco de Rodolfo Depalma.

(2018). El derecho a la objeción de conciencia en los proyectos de ley de legalización del aborto. El Derecho, tomo 277. Cita digital: ED-DCCLXXVII-273.

Navarro-Valls, R. y Martínez Torrón, J. (2012). Conflictos entre conciencia y ley. Las objeciones de conciencia ( $2^{\mathrm{a}}$ ed.). lustel.

NeJaime, D. y Siegel, R. (2020). Guerras de conciencia en las Américas. Latin American Law Review, (05), pp. 1-30. https://doi.org/10.29263/lar05.2020.01

Padilla, N. (2018). Proyecto de ley: "aborto libre y seguro", para la conciencia, coacción y unanimidad forzadas. eIDIAL.com, DC2511.

Pawlikowski, J. (2019). Conscientious objection and the goals of medicine. En A. Stepkowski (Ed.) Contemporary challenges to conscience: legal and ethical frameworks for professional conduct (pp. 65- 81). Peter Lang Gmbh.

Pellegrino, E. D. (1990). La relación entre la autonomía y la integridad en la ética médica. Boletín de la Oficina Sanitaria Panamericana (OSP), 108(5-6), pp. 379- 390. https://iris.paho.org/ bitstream/handle/10665.2/16838/v108n\%285-6\%29p379.pdf?sequence=1\&isAllowed=y

Portela, J. G. (2006). La justificación iusnaturalista de la desobediencia civil y de la objeción de conciencia. Revista de la Facultad de Derecho y Ciencias Políticas, 36(105). pp. 341-360. https://revistas.upb.edu.co/index.php/derecho/article/view/4084

Puppinck, G. (2020). Mi deseo es la ley: los derechos del hombre sin naturaleza. F. Montesinos y M. Montes (Trads.). Ediciones Encuentro.

Ramón Michel, A.; Repka, D. y Ariza, S. (2021). Mapa de normas sobre objeción de conciencia en aborto. REDAAS (Red de Acceso al Aborto Seguro, Argentina). https://www.redaas.org. ar/objecion-de-conciencia-mapa

Riccardi, M. S. (2020). Recapitulación del Conversatorio sobre la objeción de conciencia frente al aborto: diálogos sobre un derecho fundamental. Forum. Revista del Centro de Derecho Constitucional de la Facultad de Derecho de la Pontificia Universidad Católica Argentina, (10), pp. 185-202. https://erevistas.uca.edu.ar/index.php/FORUM/article/view/3406

Sambrizzi, E. A. (2021). La objeción de conciencia en la ley 27.610. La Ley, (55), año LXXXV, tomo 2021-B, pp. 1- 3.

Sartea, C. (2016). La biojurídica entre medicina del deseo y extensión del derecho a la intimidad. Ius et Scientia. Revista electrónica de Derecho y Ciencia, 2(2), pp. 134- 144. https:// revistascientificas.us.es/index.php/ies/article/view/13233

Toller, F. (2007). El derecho a la objeción de conciencia de las instituciones. Vida y Ética, (2), año 8, pp. 163-190. https://repositorio.uca.edu.ar/bitstream/123456789/1547/1/vidayetica2007-2.pdf

De Aquino, T. (1993). Suma de Teología. Tomo // (2a ed.). BAC. 


\section{Referencias normativas}

Ley 27.610. Acceso a la Interrupción Voluntaria del Embarazo -IVE- (BO, 15/01/2021).

Ley 1920. Código Penal (BO, 03/11/1921).

Ley I-0650-2008 (San Luis). Objeción de Conciencia (BO, 31/12/2008).

Ley 25.673. Creación del Programa Nacional de Salud Sexual y Procreación Responsable (BO 22/11/2002).

Resolución 856/2017. Programa Nacional de Garantía de Calidad de la Atención Médica (BO, 13/07/2017).

\section{Referencias jurisprudenciales}

CSJN, "F. A. L. s/medida autosatisfactiva”, 13/03/2012, Fallos: 335:197.

-----, “Portillo, Alfredo s/ infr. art. 44 ley 17.531”, 18/04/1989, Fallos: 312:496.

-----, "Albarracini Nieves, Jorge Washington s/medidas precautorias", 01/06/2012, Fallos: 335:799.

-----, “D., M. A. s/ declaración de incapacidad”, 07/07/2015, Fallos: 338:556.

Corte IDH, "I. V. vs. Bolivia", Excepciones Preliminares, Fondo, Reparaciones y Costas. $30 / 11 / 2016$ 